This is an Author's Original Manuscript of an article whose final and definitive form, the Version of Record, has been published in the International Journal of Remote Sensing, Vol. 34, nº, 20 March 2013 [copyright Taylor \& Francis], available online at:http://www.tandfonline.com/[ http://dx.doi. org/10.1080/01431161.2012.730154."

\title{
IDENTIFICATION OF MATERIALS RELATED TO ACID MINE DRAINAGE USING MULTI-SOURCE SPECTRA AT S. DOMINGOS MINE, SE PORTUGAL
}

\author{
Lídia Quental $^{1}$; António Jorge Sousa ${ }^{2}$, Stuart Marsh ${ }^{3}$, Maria Manuela Abreu ${ }^{4}$ \\ ${ }^{1}$ Laboratorio Nacional de Energia e Geologia, ${ }^{2}$ CERENA, Instituto Superior Técnico, Technical University of Lisbon, ${ }^{3}$ British Geological \\ Survey ${ }^{4}$ Instituto Superior de Agronomia, Technical University of Lisbon \\ (lidia.quental@lneg.pt; ajsousa@ist.utl.pt; shm@bgs.ac.uk; manuelaabreu@isa.utl.pt)
}

\section{ABSTRACT}

Imaging spectroscopy (IS) can identify target materials at both mineralogical and geochemical level. Therefore, in environmental applications it can be used to assess contamination derived from mining activities, moving from contamination sources along pathways to receptors as Acid Mine Drainage (AMD). This can be based on the spectra of specific assemblages of minerals from spectral libraries, which can indicate $\mathrm{pH}$ values at the time of their generation and the subsequent acid generating potential. Alternatively, field spectral measurements can be used as input data for mapping algorithms. This study presents a new methodological approach developed to improve the results for mapping contamination sources and pathways, by combining multi-source spectra from both these approaches at different scales. In addition to the mineralogical libraries and field spectra already mentioned, additional endmembers spectra are used that are extracted from IS data, so as to highlight particular site phenomena otherwise undetected by the two previous approaches. The highly correlated spectra are then used as input to the Spectral Angle Mapper algorithm, to establish a map of local field spectra and also one from image endmembers. The intersection of the two maps results in an improved map, assigned in terms of correlation $\geq 0.8$ of mineralogical assemblages focused on AMD indicators. This methodology was tested in the abandoned S. Domingos Mine, in SE Portugal`s Iberian Pyrite Belt, with AMD caused by long-term exploitation of Volcanogenic Massive Sulphide deposits. Data from the HyMap ${ }^{\mathrm{TM}}$ sensor covered the area and field spectroradiometric measurements were undertaken and analysed for mineralogical and geochemical content. A fligthline containing the open pit was processed according to the aforementioned methodology, focusing directly on the target of interest and minimising errors. The final map displays the mineralogical assemblage correlations $\geq 0.8$ of variable $\mathrm{pH}$ indicators, particularly isolating a low $\mathrm{pH}$ combination of significance to the contamination in the area.

KEY-WORDS: Imaging spectroscopy, multi-source spectra, Pearson correlation matrix, Acid Mine Drainage, mineralogical correlation map

\section{Introduction}

The analysis of imaging spectroscopy (IS) or hyperspectral imaging sensors, characterized by high spectral resolution across a wide range of the electromagnetic spectrum, with dedicated algorithms, enables the identification of the chemical and mineralogical composition of the imaged target. Thus, wide fields of application can take advantage of IS capabilities. Focusing on environmental concerns such as contamination related to mining areas, several studies have provided valuable information on mineralogical assemblages with the purpose of assessing (Swayze et al., 1996; 2000; Dalton et al., 1998) and monitoring (Ong et al., 2003; Zabcic et al., 2005) areas affected by Acid Mine Drainage (AMD) and consequent release of hazardous elements into the environment. Rather than using mineralogical assemblages contained in mineralogical spectral libraries, which are processed in the identifiable spectral range of the minerals searched, another possibility is to directly map the contaminants using spectral field signatures across the Visible, Near Infra-Red (VNIR) and Short Wave Infrared (SWIR) range, properly correlated with chemical field data (Kemper and Sommer, 2003; Ben-Dor et al., 2009).

The project "Assessing and Monitoring the Environmental Impact of Mining Activities in Europe Using Advanced Earth Observation Techniques" (MINEO) also added a contribution to the environmental assessment and monitoring of mining areas, covering a diversity of mining environments and respective types of contamination (Chévrel et al., 2003, 2004). Specifically concerning the AMD environment, contamination mapping based on IS has been achieved using spectral data either of waste mining field materials (Quental et al., 2002a; 2003; 2011) or from mineralogical spectral libraries as developed by Clark et al. (1993) (Bourguignon, 2002; Bourguignon et al., 2003; Quental et al., 2003), and focused on their acid generating potential (Swayze et al., 1996; 2000; Montero et al., 2005). Thus, hot spot targets were highlighted for remediation purposes, and consequently, to minimise their impact on the surrounding environment.

These studies all take advantage of the fact that the occurrence of certain minerals indicates specific ranges of $\mathrm{pH}$ values at the time of their formation. Waste mining materials with high sulphide content are considered a primary source of AMD (Singer and Stumm, 1970; Nordstrom and Alpers, 1999; Espãna et al., 2005). When in contact with water and oxygen the sulphides react to oxidize and generate an acidic leachate which contains dissolved trace elements and sulphate. This acidic leachate is partly neutralised by hydrolysis reactions with the surrounding materials as the solution flows away from the active oxidation points leading to the accumulation of iron sulphates, oxyhydroxides and oxides in a spatial and temporal sequence that represents the buffering of the acidic solution as it moves away from its source (Swayze et al., 2000; Montero et al., 2005). In the pathway of the solution, it is then possible to identify mineralogical sequences, e.g. copiapite-jarosite-goethitehematite, with an increasing $\mathrm{pH}$ ranging from $<3$ to $>6$ or equivalent mineral`s $\mathrm{pH}$ indicators depending of the chemical composition of leacheates (Bigham et al., 1996; Nordstrom and Alpers, 1999; Swayze et al., 2000; Montero et al., 2005; Smith et al., 2006). Using IS principles it is possible to identify the unique spectral absorption characteristics of such secondary iron minerals (Clark, 1999). Further details 
on the basis for spectral interpretation and mineral identification particularly related to AMD are given in Montero et al. (2005) and Crowley et al. (2003). Thus, the mineralogical mapping of an area based on specific minerals can indicate $\mathrm{pH}$ values at the time of their generation and subsequently the acid generating potential, providing valuable information for the prioritization of remediation procedures. Alternatively, as aforementioned, field spectral measurements can indicate AMD if properly correlated with chemical field data (Kemper and Sommer, 2003). According to the nature of the problem considered and specifically concerning IS contamination mapping, both input spectral datasets, i.e. mineralogical and field measurements, may however present various drawbacks and advantages.

When using mineralogical libraries to classify IS data, the spectra are measured in the laboratory in pure samples. Mineral's laboratory spectral measurements can be compared with known and well established reference data (Clark et al., 1993; 2007). However, this approach does not take into account the highly complex mixtures of minerals under evolution in the natural environment. In fact, this procedure is suitable when pure materials, contained in the library, are on the ground, but in most real-world situations, since materials are both spatially and intimately mixed, only the strongest features are matched. Even if a few sites in a scene expose pure materials, many others are mixtures of materials (Plaza et al., 2004; 2009; 2012; Chang, 2007). These mixtures of materials within a pixel can complicate the analysis of IS information, often masking the diagnostic spectral features of materials of interest and hampering their identification (Zhang et al., 2005).

Although field spectroradiometric measurements depict the local reality of the target at a given time, if this is not properly matched with mineralogical and geochemical analysis the derived classification may lack readily identifiable spectral information and not take full advantage of IS's capabilities. Moreover, the spatial view provided by IS data and extraction of spectral information through adequate algorithms that occur in a scene, can give further information about local spectral signatures that is only occasionally detected by the other two types of spectra. In fact, taking into account the real-world situations where materials are spatially or intimately mixed, the most widely used technique analyzing IS data is to determine endmember spectra directly from the image (Plaza et al., 2004). The extraction of endmembers from an image has benefits over the use of spectra measured in the field or laboratory. Mineralogical libraries and field spectra are rarely acquired under the same conditions as airborne or satellite data and they may not adequately represent all important image retrieved endmembers. On the other hand, field spectra are usually collected from surfaces one wants to map, and thus, they have direct physical meaning for mapping purposes working as site reference data. They can provide important information that may not be depicted in an image at different scale. Imagery may provide similarly meaningful endmembers that can be considered "pure", or relatively "pure", spectra (Rogge et al., 2007). Additionally, when using image retrieved endmembers, from atmospherically corrected images this already takes into account the spectral pattern as modeled by the corrections. Thus, information from image retrieved endmembers is provided in the similar spectral and spatial scale and resolution as the area to be mapped. In order to extract the maximum spectral information for the environmental assessment of AMD using IS data, a new, hybrid methodology is applied to identify materials according to their AMD potential. It relies on the use of multi-source spectra, exploiting the contributions of all the different input spectra, i.e. mineralogical libraries, field and image retrieved endmembers. These spectra, at a multi-scale level, are correlated using the similar wavelength values. In this case, the mineralogical spectral library of United States Geological Survey (USGS, Clark et al., 1993, contained also in Clark et al., 2007), was selected.

Through this methodology both of the following are emphasized: i) local field spectroradiometric measurements assigned to known mineralogical content provide readily identifiable information on reference data; and ii) identification of meaningful hyperspectral image retrieved endmembers. The spectra with correlation $\geq 0.8$ are then input to a similarity measure of full pixel classifier (Spectral Angle Mapper, SAM, Kruse et al., 1993) generating two maps, one from image retrieved endmembers and another one from field spectra. The final map of mineralogical correlation of AMD, is the intersection of the two initial maps. The methodology is tested here on the open pit area of the S. Domingos Mine located in the Iberian Pyrite Belt.

\section{Methodology}

The methodological approach exploits the spectral characteristics of multi-source data with distinct origins at multi-scale level: i) mineralogical library; ii) local field spectroradiometric measurements; and iii) endmembers retrieved from high spectral resolution images. As a measure of the linear dependence of these data, the Pearson correlation coefficient was selected from among different similarity measures, e.g. RMSE (Roberts et al., 1998), SAM (Kruse et al., 1993), due to its being independent of scale and condensing the comparison of different data sets down to a single scalar. Contrary to the SAM, the former does not have a physical meaning. The correlation values among the three types of spectral data, serves as a means to select spectra for contamination mapping of the IS data (Figure 1). Figure 1.

For dataset i) the spectra of minerals selected according to their characteristics related to AMD, i.e. indicators of $\mathrm{pH}$ at the time of their formation, as well as other minerals existing at the study site, are taken from the USGS mineralogical spectral library as developed by Clark et al. (1993), contained also in Clark et al. (2007), and implemented in ENVI 4.8 software (ITT, 2010). These spectra were measured on a custom-modified, computer-controlled Beckman spectrometer at the USGS Denver Spectroscopy Lab. Wavelength accuracy is in the order of $0.5 \mathrm{~nm}$ in the near-IR and $0.2 \mathrm{~nm}$ in the visible. The samples measured were of variable particles size and supported by combination of different analytical methods, including X-ray diffraction, bulk chemistry from X-ray fluorescence and electron microprobe analysis. The USGS library corresponds to the most commonly used spectra in the geological community (Rivard et al., 2008). For dataset ii) field spectra collected in the study area with a spectrometer contribute ground reference information. In this case the ASD FieldSpecPro spectrometer was used with spectral sampling varying from $1.4 \mathrm{~nm}$ to $2 \mathrm{~nm}$ and spectral resolution from $3 \mathrm{~nm}$ to $12 \mathrm{~nm}$ and wavelength accuracy of $1 \mathrm{~nm}$.

For dataset iii), among the different types of algorithms used to extract endmembers from images, e.g. as referred in Plaza et al. (2012), a sequence of a Minimum Noise Fraction (MNF) transform (Boardman et al., 1994) as modified from Green et al. (1988), Pixel Purity Index (PPI) (Boardman et al., 1995) and n-D visualiser were selected. These algorithms were implemented in ENVI software (ITT, 2010) and follow a protocol designated as Automated Spectral Hourglass, where the prediction of endmembers can be done in an automatic manner.

From the image retrieved endmembers spectra, those not related to the mapping target, i.e. indicators of AMD based on iron sulphates, oxyhydroxides and oxides, are excluded which encompasses vegetation patterns or errors in the image. Jointly with field spectra and the mineral spectral library, they are correlated through the Pearson correlation matrix according to the similar wavelength values of spectral bands. For data where differences exist, the wavelength value is resampled to the smallest near value. In this case the ANDAD software (Sousa and Sousa, 2000) was used to do this. Establishing the correlation among these multi-source spectral data, i.e. i), ii) and iii), two 
features are highlighted: a) potentially relevant endmembers provided by a wide spatial and spectral view and scale, based on the IS images, and b) the relationship of field spectra of a specific target and their acid generating potential, based on mineralogical assemblages derived from individual minerals of spectral libraries.

In order to improve the next steps of classification, a threshold of correlation value $\geq 0.80$ is applied to both the field and image retrieved endmember spectra. These are also focused on AMD mineral indicators, as derived from their correlation with the USGS mineralogical spectral library. This approach is used to select spectra for the spatial mapping of AMD in the IS image using the Spectral Angle Mapper (SAM) algorithm (Kruse et al., 1993).

The SAM is an algorithm which is a physically-based spectral classification to match pixel spectra to reference spectra. The algorithm determines the spectral similarity between two spectra by calculating the angle between the spectra, treating them as vectors in a space with dimensionality equal to the number of bands. In this case, the angle between IS image and multi-source spectra are compared.

Two maps result from SAM, one from field spectral data and the other from endmembers, both being interpreted in terms of correlations with the USGS mineralogical spectral library (Clark et al., 1993). Thus, each pixel of both maps is assigned to the minerals with correlation values $\geq 0.80$, i.e. they are converted to the mineral correlation values established.

Performance is improved by eliminating pixels mapped only for one type of input spectra, so that the final map is the intersection of the two previous maps. For each input map, respectively derived from field spectra and from image retrieved endmembers, the pixels containing the same assigned minerals are spatially merged above the correlation threshold $\geq 0.80$ and then intersected. This intersection is executed by combining spatial pixels with identical mineral assemblages above the threshold correlation value mentioned. In this way, the dispersion pattern of the most relevant minerals for the area, in particular the ones which indicate a low $\mathrm{pH}$ value and thus environmental hot spot targets, are highlighted.

\section{Test Site and Data sets}

\subsection{Characteristics of the test site: S.Domingos Mine}

The now abandoned S. Domingos Mine (SD) is located within the Iberian Pyrite Belt, known worldwide as the Metallogenic Province for Volcanogenic Massive Sulphides (VMS) deposits within the Iberian Peninsula. The former mine, in southeastern Portugal close to the border with Spain, is approximately sixty kilometers SE of Beja. The mining activity started in pre-Roman and Roman times with the exploitation of $\mathrm{Ag}, \mathrm{Au}$ and $\mathrm{Cu}$ in the gossan and afterwards in modern times, in the middle $19^{\text {th }}$ century for $\mathrm{Cu}$ and $\mathrm{S}$, secondarily for $\mathrm{Au}, \mathrm{Pb}$ and $\mathrm{Zn}$ both in the gossan and VMS. Mining ceased in 1966 due to the exhaustion of the ore and production has been estimated at more than 25Mt (Carvalho, 1979), while waste mining materials are themselves estimated to be in the range of several million tons.

Compatible with the volume of the ore extracted and processed, the AMD was intensive with effects that endure until today. The development of several mining infrastructures for exploitation, processing and transportation of the ore, including sulphur plants, facilitated the dispersion of mine waste materials and related pollutants over an area of $50 \mathrm{~km}^{2}$ (Quental et al., 2002a;b) (Figure 2a).

\section{Figure 2.}

No remediation measures have been applied to the area, allowing for a complex geochemical evolution under semiarid conditions. According to the Thornthwaite classification, the climate of the region is semiarid mesothermic, with no excess water and small thermal efficiency in the hot season, and it can be divided in two distinct seasons, a wet period from November to March and a dry period from May to September. The annual average air temperature is $17.6^{\circ} \mathrm{C}$, and annual precipitation is $559 \mathrm{~mm}$ (Abreu et al., 2008).

\subsection{Airborne hyperspectral data from HyMap ${ }^{\mathrm{TM}}$}

The HyMap ${ }^{\mathrm{TM}}$ sensor owned by Hyvista Corporation (HVC), covers the spectral range 450 to- $2500 \mathrm{~nm}$, with a spectral bandwidth varying between 10-20 nm and a signal to noise ratio better than 500/1 (Cocks et al.,1998). HVC used a Dornier 228 aircraft operated by the Deutsches Zentrum für Luft und Raumfahrt (DLR) to acquire HyMap data over the S. Domingos mining area on 21 of August 2000. The ground instantaneous field of view for these data is $4.3 \mathrm{~m}$. The dataset was provided as radiance by HVC, as well as calibrated to reflectance using HyCorr software, which is a modified version of the ATmospheric REMoval (ATREM) software (Gao et al., 1999). An Empirical Flat Field Optimal Reflectance Transformation ${ }^{\mathrm{TM}}$ (EFFORT) polishing was implemented in the ENVI software (Quental et al., 2011). The EFFORT as described by Goetz (1997) and Boardman (1998) is an analytical process that bootstraps a linear adjustment to apparent reflectance spectra to improve the accuracy of spectra following calibration with ATREM. This improves the comparison with library-based spectra, the basis of many of the image interpretation methods.

The fligthlines were geocoded in UTM, WGS84 datum using DGPS flight data. An overview of the area is given by the mosaiced fligthlines in Figure 2a, while the fligthline encompassing the open pit tested in this work is depicted in Figure $2 b$.

\subsection{Field data}

\subsubsection{Spectroradiometric measurements}

Field spectra were collected across the area with an ASD FieldSpec@Pro spectrometer, with wavelengths between 350-2500 nm, in August 2001. The collection was focused on selected targets depicted in Figure 2a) and named S. Domingos (SD), Tapada (TA); Achada do Gamo (AC); Telheiro (TE); Pomarão North (PN) and Pomarão South (PS). These subareas were selected inside of the main area of the airborne hyperspectral dataset capture, taking into account the diversity of geological features, mining aspects and environmental issues (Quental et al., 
2002 a and b). Particular emphasis was given to supposedly contaminated targets, respectively SD, AC, TE and PS, while TA and PN are considered to be background areas. Based on the geochemical concentration of some of the targets, their field descriptions and spectral characteristics, 92 spectra were selected for this work.

\subsubsection{Soils and mine waste materials}

Soil and mine waste material samples collected (Figure 2) for the contaminated subareas of SD presented high anomalies of several chemical elements such as As, $\mathrm{Cu}, \mathrm{Pb}$ and S (Quental et. 2002a; b; Abreu et al., 2004). The other two contaminated subareas (AC and TE), presented high values mainly in $\mathrm{As}, \mathrm{Hg}, \mathrm{Pb}$ and $\mathrm{Sb}$ (Tavares et al., 2008; 2009).

X-Ray Diffraction analysis of the soil clay fraction $(<2 \mu \mathrm{m})$ for the non-contaminated subareas of TA and PN (Figure 2a) shows that the soils are mainly composed of mica, kaolinite, quartz, interstratified mica-vermiculite, berthierine, halloysite, hematite and vermiculite. In the contaminated subareas of $\mathrm{SD}, \mathrm{AC}$ and $\mathrm{TE}$ the soil clay fraction contained mica, kaolinite, hydroxy-interlayer $\mathrm{Al} / \mathrm{Fe}$ vermiculite, quartz, goethite, hematite, and halloysite.

Jarosite, natrojarosite, anglesite and plumbogummite salts were identified in the materials of SD, TE and AC (the contaminated subareas). Salt efflorescence, only recognised in $\mathrm{AC}$ and $\mathrm{SD}$ sub-areas, showed a mixture of complex hydrated sulphates of $\mathrm{Pb}, \mathrm{Cu}, \mathrm{Zn}, \mathrm{K}, \mathrm{Al}, \mathrm{As}, \mathrm{Fe}$ and $\mathrm{Ca}$. A mixture of copiapite and rumerite has been recognised in AC. Alunite was also identified in SD.

Jarosite only occurred in soil samples with $\mathrm{pH}<4.2$, whereas the hydroxy-interlayer $\mathrm{Al} / \mathrm{Fe}$ vermiculite occurs in soil samples where $\mathrm{pH}$ lies between 3.5 and 6. This clay mineral does not occur in soils developed on dumps, which were not leached by acid waters (SD), even if the $\mathrm{pH}$ lies in the same range (Quental et al., 2002a).

\section{Results}

\subsection{Correlation matrix of spectral data}

The ASD field spectra collected in the sub-areas were visually analysed, with the vegetation excluded. Selected minerals from the USGS spectral mineralogical library (Clark et al., 1993; 2007), taking into account global mineralogical field results for the area and AMD indicators, and extracted endmembers from Hymap ${ }^{\mathrm{TM}}$ also excluding vegetation and image errors, were correlated in the ANDAD software (Sousa and Sousa, 2000) based on similar wavelength values, resampled when necessary. Excluding also noisy bands such as strong water vapour bands and a few others either from ASDFieldSpecPro or in Hymap ${ }^{\mathrm{TM}}$, the wavelength values used were the ranges 449-1337 nm, $1434-1782 \mathrm{~nm}$ and $1989-2470 \mathrm{~nm}$ corresponding to 118 bands.

Table I presents the characteristics of the USGS spectral library minerals that have correlation $\geq 0.80$ with the other two types of data, namely field spectral data and image endmembers (Table II).

Table I

Table II

Examples in spectral space of the spectra most highly correlated with low pH minerals are given in Figure 3.

Figure 3.

It is clear that relevant spectra related to AMD may present a relatively flat pattern and not sharp absorption features that can be easily identified, particularly in the field spectra (Figure 3b). Some of the minerals spectra themselves are rather flat or with broad absorption features, e.g. copiapite, as well as the signatures of most mixed materials either from image or from field spectra, which determined the use of the entire above mentioned wavelength range.

From the 92 ASD field spectral measurements selected, 23 present high correlations with the USGS library. From the 96 image endmembers extracted from Hymap ${ }^{\mathrm{TM}}$ image, 20 spectra also present a high correlation with the USGS library. However, 10 of them are related solely to minerals not relevant for the objective of the work (e.g. quartz, and a-smectite) that do not indicate acid generating potential or buffering capacity and were excluded from further analysis. Two more were excluded due to the fact that copiapite and alunite were below 0.80 correlation values. Thus, only 8 image-derived spectra directly related to the acid generating potential remain for further processing.

\subsection{Spectral Angle Mapper (SAM)}

The SAM inputs the field and image retrieved endmember spectra that have correlations $\geq 0.80$ with USGS library expressed in Table II, using a 0.1 radians angle ${ }^{1}$.

${ }^{1}$ Referred to as the cosine in ENVI (ITT, 2010) and not as the inverse, as formally defined (Chang, 2007). Although different angles have been tested the option was to maintain a standard value, equal for all the spectra, and rely on a correlation value indicator of the input spectra to improve the classification. 
This algorithm produces the two intermediate maps (Figure 1) of spatial distribution of spectra, which each have high correlations with the USGS spectral library minerals (Table II): Figure 4 depicts the pattern of highly correlated field spectra, while Figure 5 shows the pattern of the correlated endmembers retrieved from the HyMap ${ }^{\mathrm{TM}}$ image.

Further details are given in both about $\%$ of classified classes and also the statistical parameter coefficient ${ }^{2}$ of variation (CV), in order to compare the homogeneity of the classes. The intersection of the two maps is done by assigning each pixel to classes, according to the value of correlation of mineralogical assemblages after Table II, and then spatially merging the identical spectral pixels. The final map is depicted in Figure 6. In this, each of the minerals discriminated in the subtypes in Table II, e.g. J1 (jarosite 1) or J2 (jarosite 2) is summarised in just one type (jarosite). This is done to facilitate the comprehension of the spatial dispersion pattern of minerals over the area. For the intersection, not all $\geq 0.80$ correlations mapped are considered due to the focus on AMD, but rather the minerals that are connected to the acid producing capabilities (red-yellow classes) or not (orange-brownish classes). Also, the classes that contain several minerals of distinct $\mathrm{pH}$ were not considered, as they are not clear indicators of a specific $\mathrm{pH}$. The classes resulting from spatially merged pixels are depicted in Figure 6. The minerals in brackets refer to non-acid generating minerals present in the correlation matrix in field and image endmember spectra. An exception to this is the quartz and illite in the jarosite class, due to the fact that it reports only to their occurrence in the image endmember class. This has been maintained, as neither of the two minerals are as clearly environmental indicators as the different iron secondary minerals. The spectra below in Figure 6 correspond to the averages of the classes of the merged pixels.

Figure 4

Figure 5

Figure 6

Details of the three maps are given in Table III, considering the area occupied and the CV.

Table III

\section{Discussion}

\subsection{Correlation Matrix}

Values from Table II show that correlations $\geq 0.80$ are achieved, indicating the strength of the linear relationship among the input spectra despite the multiple scales.

It is also observed that the correlation of the USGS spectral library minerals with field spectral measurements indicate a much higher global correlation, namely $\geq 0.90$, when compared with the global correlation of endmembers derived from the hyperspectral image (Table II), and also show a much greater variability of minerals. In contrast, only two correlations $\geq 0.90$, can be detected on the correlation of the USGS spectral library minerals and image endmembers and the mineralogical diversity is much lower. This is thought to be explained by the large pixel dimensions, when compared to the much more localised point measurement of field spectra, and also by the effect of the atmospheric corrections undertaken in smoothing the signal with the EFFORT polishing (Section 3.2). It must also be stressed that the higher variability expressed in the X-Ray Diffraction results (Section 3.3.2) without equivalent available data on spectral libraries, implies a higher mineral complexity in the target analysed.

These mineralogical assemblages provide indications about $\mathrm{pH}$ values at the time of the minerals' formation. The accumulation of specific types of minerals is a function of the $\mathrm{pH}$ values and the chemical content of leachates. Copiapite $\left[\mathrm{Fe}^{2+} \mathrm{Fe}^{3+} 4\left(\mathrm{SO}_{4}\right)_{6}(\mathrm{OH})_{2} \cdot 20\left(\mathrm{H}_{2} \mathrm{O}\right)\right]$ and jarosite $\left[\mathrm{KFe}_{3}\left(\mathrm{SO}_{4}\right)_{2}(\mathrm{OH})_{6}\right]$ form at $\mathrm{pH}$ values $<3$, and precipitate near sources of acidity that are also sources of iron and trace elements (Nordstrom and Alpers, 1999; Smith et al., 2006). However, jarosite may also precipitate at higher pH values of waters, i.e. 3.8 as referred to in Bigham et al. (1996). Goethite $[\alpha-\mathrm{FeOOH}]$ forms at $\mathrm{pH}$ values generally less than 6 from the dissolution of previous minerals, including early-formed goethite, and so precipitates farther from contaminant sources. Hematite $\left[\alpha-\mathrm{Fe}_{2} \mathrm{O}_{3}\right]$ accumulates even farther from the sources of acidity, after forming in a $\mathrm{pH}$ dependent process that may involve the dehydration and transformation of earlier precipitates, such as those of goethite and ferrihydrite (Montero et al., 2005). The latter usually occurs at pH 6.5 or higher (Bigham et al., 1996).

The mineralogical correlations obtained highlight the mineralogical assemblage of copiapite and types of alunite, whether with the presence of a-smectite, illite or kaolinite (Table II), and the exclusion of any other iron secondary minerals, in particular of jarosite.

Although copiapite and jarosite appear as the minerals with the lowest $\mathrm{pH}$ values in the sulphide oxidation pathway (Nordstrom and Alpers, 1999; Smith et al., 2006), this split appears to confirm a higher $\mathrm{pH}$ precipitation value for jarosite, suggesting a threshold of $\mathrm{pH}$ values detectable in the spectral data. The correlation values (Table II) are only above $\geq 0.90$ for the endmembers for this specific copiapite-alunite

${ }^{2}$ Coefficient of variation $(\mathrm{CV})=\sigma /$ aver, whereas $\sigma=$ standard deviation and aver $=$ average of data distribution. 
assemblage, depicting a strong isolated relationship. This assemblage equates in the previously reported field spectra mapping (Quental et al., 2002a; 2011) to the class defined as mixed sulphur materials, corresponding to high acid producing material.

Using detailed information about the type of mineralogical spectral library allows further environmental knowledge of the minerals present to be extracted, e.g. the specific type of goethites or jarosites. This information can serve as environmental indicators, based on the mineral's capabilities to sequester hazardous elements, as in the case of jarosite and lead. Once such elements are in the form of stable minerals it significantly reduces their dispersion in soils and rivers (Figueiredo and Silva, 2011). As an example, the correlation with USGS "Jarosite WS368 Pb" contains $\mathrm{Pb}$. However, in this test fligthline, this was only verified at point spectra level, i.e. at field measurements and endmembers, but is not seen in the image scale final map.

\subsection{HyMap ${ }^{\mathrm{Tm}}$ mapping}

Comparing the maps derived from field spectra (Figure 4) with the map derived from image endmembers (Figure 5), the spatial pattern is quite distinct. The field spectra map a smaller area than the image endmembers, even if the number of ASD spectra is higher (23) than the endmembers input spectra (8). Although both maps have a low coefficient of variation $(\mathrm{CV}<1)$, implying low variability data and probably absence of anomalous data, this value tends to be lower in most of the endmember classes. The variability already detected at a mineralogical level in the Pearson correlation matrix for field and endmember spectra is translated to the image mapping. While the field spectra map depicts as a major pattern several secondary iron mineral assemblages, implying a high but unclear $\mathrm{pH}$ value (FGHIJL class, Table III), the endmembers map shows the major areas connected to environmental indicators such as jarosite. In fact, in the ASD field map the mapped areas increase from low to higher $\mathrm{pH}$ classes, i.e. copiapite-alunite to jarosite and mixed secondary Fe minerals classes, while in the endmembers map the major areas are covered by jarosite. The final AMD correlation map follows the same distribution pattern as the ASD field map except that, in the case of the jarosite class, the $\mathrm{CV}$ is higher than from both input maps $(\mathrm{CV}=0.399)$, possibly due to a very small intersection area with wider variability.

The final mapped areas (Table III) decrease when compared to the initial maps. It's worth noticing that in previous works (Bourguignon, 2002, Bourguignon et al., 2003, Quental et al., 2002a), the spatial intersection of two mineralogical maps, each using different mapping algorithms and solely USGS libraries as input data, also decrease the final mapped areas. The final AMD mineralogical correlation map shows the copiapite-alunite dispersion surrounding acidic water dams, i.e. the inundated open pit, following the railway path and the southern dams. A few other pixels from this class were detected west of the north end of Tapada Pequena, in connection with the jarosite class, as well as in the border of the Tapada Grande and Tapada Pequena dams (Figure 2b). To the south of the open pit, waste piles also contain a few pixels of copiapite-alunite.

The jarosite (illite, quartz) class is concentrated to the west in the waste materials of the open pit, to the west, and to the northwest, in a more acidic area connected with the geological background materials. This class also depicts a more dispersed pattern in the village, where part of the ground is composed of waste materials, and also following the railway path. This shows that the dispersion of hazardous materials is not limited to the areas of exploitation but has been spread out by a variety of human activities undertaken over long periods of time, including the use of these materials for construction purposes, as is the case for the Tapada Pequena and Tapada Grande water dams. Alternatively, the red brick roofs may present a similar spectral pattern due to the presence of $\mathrm{Fe}^{3+}$ and phyllosilicates and may also contribute for this pattern in the village.

The occurrence of a large area, i.e. $21,855 \mathrm{~m}^{2}$ (Table III), with only jarosite as a secondary iron mineral is very significant because it seems to extend the $\mathrm{pH}$ threshold to limits higher than 3.5, as previously suggested by Montero et al. (2005), if applied to this test site. This is supported by field data, where jarosite occurs in soil samples with $\mathrm{pH}$ values up to 4.2. Also, work by Hammerstrom et al. (2005) seems to imply a precipitation of jarosite not under very low $\mathrm{pH}$ waters, but driven instead by potassium availability.

From the spectral point of view, the average values do not display significant changes among the three types of classes (Figure 6), slightly improving when a continuum removal is applied. In fact, many of the minerals of the three classes have a broad spectral absorption feature associated with $\mathrm{Fe}^{2+}$ or $\mathrm{Fe}^{3+}$ (Crowley et al., 2003), so a continuum removal facilitates their comparison. All three AMD correlation classes depict strong absorption features at 492, 692 and $2206 \mathrm{~nm}$. Shared smaller features are present at 2326 and $2391 \mathrm{~nm}$, while a small feature at $1168 \mathrm{~nm}$ is depicted for both copiapite-alunite and jarosite classes. The feature at $2358 \mathrm{~nm}$ is absent from the jarosite class.

Amongst these, the copiapite-alunite class displays sharper absorption features, exclusively occurring at 859, 875, 902 and $953 \mathrm{~nm}$ wavelengths. These values differ from the copiapite absorption features $(434,547,883,914,2205,2295,2400,2440 \mathrm{~nm})$ as well as from the alunites in USGS libraries of Clark et al. (1993).

The reasons for the absence of, or shifts in, the standard library absorption features may be primarily related to the fact that the classes obtained are mixtures, rather than pure materials as depicted in the USGS spectral libraries. The grain size may also contribute to this variation in spectral absorption features.

(Figure 6).

\subsection{Advantages of the method employed}

Classical validation techniques may not be appropriate when applied to Imaging Spectroscopy, as the imagery is at times able to map the environment with greater accuracy than can be obtained by field crews or maps produced by various methods other than remote sensing (Jacquez et al., 2002; Aspinall et al., 2002; Foody, 2008). This is particularly relevant when the objective is mineralogical or chemical mapping, when ground reference data collection must deal with significant scaling from field ground reference points to pixel sized image samples, most often with mixed pixels. The multi-source methodology tested makes a contribution to resolving this issue by using spectral data sources that address these different spatial and sampling scales but are still highly correlated spectrally. Each source contributes with a different component to the final mapping. The field spectral data provides validation by ground reference data, while the endmembers from 
the image provide a spatial overview with contiguous spectral data and the USGS spectral library ties the results to known mineralogy. The extraction of endmembers, as detailed in Section 2, has benefits over the use of spectra measured in the field or laboratory.

The Pearson Correlation matrix using multi-source spectral data, i.e. image retrieved endmembers, field spectra and mineralogical libraries has two major benefits: i) it provides mineralogical information to unknown spectra, and ii) it selects information from amongst a huge amount of spectral data, focusing on the subject of interest (in this case AMD) by using only the most relevant mineral assemblages. Thus, the required input spectra for mapping are minimized and correspond only to highly correlated spectra.

In i), a lot of information is retrieved concerning the mineralogical content, which is coherent with field descriptions and with chemical analysis. Using detailed information about the type of mineralogical spectral library allows the extraction of further environmental knowledge of the minerals present, e.g. the type of goethites or jarosites.

The fact that two types of maps are produced, i.e. field spectra and endmembers, and the final map is expressed in terms of the mineralogical assemblages' intersection, also contributes to a better result, as contributions to the final result have come from two types of mapping.

Finally, this methodology overcomes some of the difficulties encountered in previous studies, whereby image results are difficult to reconcile with field data, or have obscure mineralogical meaning, by minimising the gap among different spectral data, i.e., field (ASD FielsSpecPro), laboratory measurements (USGS libraries) and airborne images $\left(\right.$ HyMap $\left.^{\mathrm{TM}}\right)$ data.

\section{Conclusions and final remarks}

The methodology applied provides a simple way of taking advantage of multi-source, multi-scale spectral data, highlighting and focusing immediately on the target of interest, whether for environmental or for exploration purposes. The USGS mineralogical spectral library (Clark et al., 1993; 2007) provides the link depicting the mineralogical assemblages contained in field spectra and image endmembers. This allows the target of interest to be focused on, by selecting only the high correlations of specific, relevant mineral assemblages. The quantitative correlation established to link these distinct spectral sources minimises the errors related to anomalous data. It is also a way of using ground reference data to improve the results of IS mapping, by creating two different types of maps, and using solely the identically classified pixels in both mapping outputs, i.e. image retrieved endmember and field spectra.

In this specific test site, by detailing the mineralogical and spectral content of the data it has been possible to detect the exclusivity of an AMD signature based on mineralogical assemblages of copiapite with alunites, whether accompanied with a-smectite, illite or kaolinite, whereas jarosite was completely split into another class. This suggests that a significant $\mathrm{pH}$ threshold has been detected spectrally, extending the range of potential applications for IS data.

\section{Acknowledgements}

The dataset was collected in the framework of the MINEO project in the $5^{\text {th }}$ FP (IST-1999-10337) of EU. We are grateful to Dr. Hartmut Mollat from BGR, responsible for the field spectroradiometric measurements as well as for his suggestions, during data capture. Two anonymous reviewers contributed to improve the work.

This work was partially funded through Foundation for Science and Technology of Portugal (Grant BD/17257/2004).

Published with the approval of the Executive Director, British Geological Survey.

\section{References}

Abreu, M.M., Tavares, M.T., Batista, M.J. (2008). Potential use of Erica andevalensis and Erica australis in phytoremediation of sulphide mine environments: São Domingos, Portugal. Journal of Geochemical Exploration 96 (2008) 210-222.

Abreu, M. M., Tavares, M.T., Vairinho, M. M., Joaquim, C., Quental, L. (2004). Geoquímica comparada dos solos da área mineira de São Domingos, Alentejo: fundo geoquímico versus zona de exploração. Revista de Ciências Agrárias, 27 (1): 301-313.

Aspinall R.J, Marcus W.A, Boardman J. (2002). Considerations in collecting, processing, and analyzing high spatial resolution and hyperspectral images in analyses and forcasts. Journal of Geographical Systems 4:15-29.

Ben-Dor, E., Chabrillat, S., Demattê, J.A.M., Taylor, G.R., Hill, J., Whiting, M.L., Sommer, S. (2009). Using Imaging Spectroscopy to study soil properties. Remote Sensing of Environment, Volume 113, Supplement 1, Imaging Spectroscopy Special Issue, pp S38-S55.

Bigham, J.M., Schwertmann, U.S., Traina, J., Winland, R. L., Wolff, M. (1996). Schwertmannite and the chemical modeling of iron in acid sulfate waters. Geochimica et Cosmochimica Acta, Vol. 60 (12): 2111-2121.

Boardman, J.W. (1989). Inversion of imaging spectrometry data using singular value decomposition: in Proceedings, IGARSS'89, 12th Canadian Symposium on Remote Sensing, v. 4., pp. 2069-2072.

Boardman, J.W., Kruse, F.A. (1994). Automated spectral analysis: a geological example using AVIRIS data, north Grapevine Mountains, Nevada: in Proceedings, ERIM Tenth Thematic Conference on Geologic Remote Sensing, Environmental Research Institute of Michigan, Ann Arbor, MI, pp. I-407 - I-418.

Boardman, J.W., Kruse, F.A., Green, R.O. (1995). Mapping target signatures via partial unmixing of AVIRIS data: in Summaries, Fifth JPL Airborne Earth Science Workshop, JPL Publication 95-1, v. 1, pp. 23-26.

Bourguignon, A. (2002). MINEO SÃO DOMINGOS AMD mineral mapping. Intersection pixels mapped with MTMF and SAM. In Ap. 6.5 of the MINEO Southern environment test site. Contamination/impact mapping and modeling (2002a), final report for European Comission, 131.

Bourguignon, A., Quental, L., Cottard, F., Hosford, S., Chevrel, S. (2003). Hyperspectral Investigations of Mining-Related Contaminated Areas: Acid Mine Drainage Mineral Identification Comparison Between Field and Airborne Data (Sao Domingos Mine, Southeast Portugal), 3rd EARSel Workshop on Imaging Spectroscopy, DLR, Munich, Germany. 
Carvalho, D. (1979). Geologia, metalogenia e metodologia da investigação de sulfuretos polimetálicos do sul de Portugal. Comunicações dos Serviços Geológicos de Portugal, t. 6:,169-191.

Chang, C (2007). Hyperspectral Data Exploitation: Theory and Applications. ISBN: 978-0-471-74697-3. Willey. 440p.

Chevrel, S., Kuosmanen, V., Groesel, K., Marsh, S.H., Tukiainen, T., Schaeffer, U., Quental, L., Vosen, P., Loudjani, p., Kuronen, E. and Aastrup, P. (2003). Remote sensing monitoring of environmental impacts. Mining Environmental Management, 11(6): 19-23.

Chevrel. S., Kuosmanen, V., Groesel, K., Marsh, S., Tukainen, T., Schaeffer, U., Quental, L., Vosen, P., Loudjani, P., Astrup P. (2004). Hyperspectral Remote-Sensing Assessment Of Mining-Related Environmental Impacts - Examples From The Mineo Project. Abstracts Of The 32nd International Geological Congress, 247-1 Url: Http://Www.32igc.Org/Scientific_Session_Warning.Htm Available On January 2009

Clark, R. N. (1999). Spectroscopy of Rocks and Minerals, and Principles of Spectroscopy, in Manual of Remote Sensing, Volume 3, Remote Sensing for the Earth Sciences, (A.N. Rencz, ed.) John Wiley and Sons, New York, p 3-58.

Clark, R.N., Swayze, G.A., Gallagher, A.J., King, T.V.V., Calvin, W.M. (1993). The U. S. Geological Survey, Digital Spectral Library: Version 1: 0.2 to 3.0 microns, U.S. Geological Survey Open File Report 93-592, 1340 pages.

Clark, R.N., Swayze, G.A., Wise, R., Livo, E., Hoefen, T., Kokaly, R., Sutley, S.J. (2007). USGS digital spectral library splib06a: U.S. Geological Survey, Digital Data Series 231, http://speclab.cr.usgs.gov/spectral.lib06.

Cocks T., R. Jenssen, A. Stewart, I. Wilson, T. Shields (1998). The HyMap Airborne Hyperspectral Sensor: The System, Calibration and Performance. Proc. 1st EARSeL Workshop on Imaging Spectroscopy (M. Schaepman, D. Schläpfer, and K.I. Itten, Eds.), 6-8 October 1998, Zurich, EARSeL, Paris, p. 37-43.

Crowley, J.K., Williams, D.E., Hammarstrom, J.M., Piatak, N., Ming Chou, I., Mars, J.C. (2003). Spectral reflectance properties (0.4-2.5 um) of secondary Fe-oxide, Fe-hydroxide, and Fe-sulphate-hydrate minerals associated with sulphide-bearing mine wastes. Geochemistry: Exploration, Environment, Analysis; v. 3; no. 3; p. 219-228; DOI: 10.1144/1467-7873/03-001.

Crowley J. K., Hubbard B. E., Mars J. C. (2003). Analysis of potential debris flow source areas on Mount Shasta, California, by using airborne and satellite remote sensing data. Remote Sensing of Environment, Vol. 87, 2-3, 345-358.

Dalton, J.B., King, T.V.V., Bove, D.J., Kokaly, R.F., Clark, R.N., Swayze, G.A. (1998). Mapping of acid-generating and acid buffering minerals in the Animas watershed by AVIRIS spectroscopy. Proc. 7th AVIRIS Earth Sci. Workshop, JPL, vols. 97-21, 4 pp.

Espãna, J.S., Pamo, E.L., Pastor, E.S., Andrés, J.R., Rubí, J.M. (2005). The natural attenuation of two acidic effluents in Tharsis and La ZarzaPerrunal mines (Iberian Pyrite Belt, Huelva, Spain). Environmental Geology, 49: 253-266.

Figueiredo, M.O, Silva, T.P. (2011) The Positive Environmental Contribution of Jarosite by Retaining Lead in Acid Mine Drainage Areas. Int. J. Environ. Res. Public Health 2011, 8, 1575-1582; doi:10.3390/ijerph8051575

Foody, G. (2008). Harshness in image classification accuracy assessment. International Journal of Remote Sensing, Vol. 29 , 11, $3137-3158$.

Gao, B.-C.; Hiedebrecht, K.B., Goetz, A.F.H. (1999). Atmosphere Removal Program. (ATREM) User's Guide version 3.1 pp.101.

Green, A.A., Berman, M., Switzer, P, Craig, M.D. (1988). A transformation for ordering multispectral data in terms of image quality with implications for noise removal: IEEE Transactions on Geoscience and Remote Sensing, Vol. 26, 1, 65-74.

Hammarstrom, J.M, Seal I.I, RR, Meier, A.L, Kornfeld, J.M. (2005). Secondary sulfate minerals associated with acid drainage in the eastern US: recycling of metals and acidity in surficial environments. Chemical Geology, 215: 407-431.

ITT (2010). Envi Users Guide:Version 4.8.ITT Visual Information Solutions.

Jacquez, M., Marcus, W.A., Aspinall R.J., Greiling, D.A. (2002). Journal of Geographical Systems, Vol. 4, 1, 1-14.

Kemper, T., Sommer, S. (2003). Mapping and monitoring of residual heavy metal contamination and acidification risk after the Aznalcóllar mining accident (Andalusia, Spain) using field and airborne hyperspectral data. In M. Habermeyer, A. Müller, \& S. Holzwarth (Eds.), Proceedings of 3rd EARSEL Imaging Spectroscopy, Herrsching, Germany, May 13-16 2003,. CD-ROM ISBN 2-908885-56-5, 333343.

Kruse, F.A., Lefkoff, A.B., Boardman, J.B., Heidebrecht, K.B., Shapiro, A.T., Barloon, P.J., Goetz, A.F.H. (1993). The Spectral Image Processing System (SIPS) - Interactive Visualization and Analysis of Imaging spectrometer Data". Remote Sensing of Environment, vol. 44, $145-163$.

Montero, I.C., Brimhalla, G.H., Alpers, C.N., Swayze, G.A. (2005). Characterization of waste rock associated with acid drainage at the Penn Mine, California, by ground-based visible to short-wave infrared reflectance spectroscopy assisted by digital mapping. Chemical Geology, 215: 453-472.

Nordstrom, D.K., Alpers, C.N. (1999). Geochemistry of acid mine waters. In: Plumlee, G.S., Logsdon, M.J. (Eds.), The Environmental Geochemistry of Mineral Deposits: Part A. Processes, Techniques, and Health Issues, Review of Economic Geology, Vol. 6A, 133-155.

Ong, C., Swayze, G., Clark, R. (2003). An investigation of the use of the Tetracorder Expert System for multi-temporal mapping of Acid Drainage - related minerals using Airborne Hyperspectral Data. Proceedings of 3rd EARSEL Imaging Spectroscopy, Germany, 357362.

Plaza, A., Martinez, P., Perez, R., Plaza, J. (2004). A new approach to mixed pixel classification of hyperspectral imagery based on extended morphological profiles, Pattern Recognition, Vol. 37, Issue 6, 1097-1116.Plaza, A., Benediktsson, J. A., Boardman, J., Brazile, J., Bruzzone, L., Camps-Valls, G., Chanussot, J., Fauvel, M., Gamba, P., Gualtieri, A., Marconcini, M., Tilton, J.C., Trianni, G.(2009). Recent advances in techniques for hyperspectral image processing, Remote Sensing of Environment, Vol. 113, Supplement 1, pp. S110S122.

Plaza, J., Hendrix, E., García, I., Martinez, G., Plaza., A. (2012). On Endmember Identification in Hyperspectral Images Without Pure Pixels: A Comparison of Algorithms. J. Math Imaging, 42:163-175163-175. DOI 10.1007/s10851-011-0276-0.

Quental, L., Bourguignon, A., Batista, M.J., Brito G., Abreu, M.M., Vairinho, M., Sousa, A.J., Cottard, F. (2002a). MINEO Southern environment test site. Contamination/impact mapping and modelling - Final report for European Comission. 131.

Quental, L. Abreu, M.M, Oliveira, V., Sousa, P., Batista, M.J., Brito, G., Vairinho, M., Sousa, J., Martins, L. (2002b). Imagens Hiperespectrais Para Avaliação E Monitorização Ambiental Em Áreas Mineiras: Resultados Preliminares Do Projecto Mineo Na Mina De São Domingos, Alentejo. In Actas do Congresso Internacional sobre Património Geológico e Mineiro. Museu do Instituto Geológico e Mineiro. Brandão, J. (ed.) Lisboa, ISBN 972 98469-8-7. 583-595.

Quental, L., Bourguignon, A., Cottard, F., Brito, M.G., Abreu, M.M., Sousa, A.J. Vairinho, M. (2003). Use Of Airborne Hyperspectral Imagery For Contamination Mapping At São Domingos Mine, Iberian Pyrite Belt, Southeast Portugal. Proceedings of 4th European Congress on Regional Geoscientific Cartography and Information Systems, Vol. II, 698-699.

Quental, L. Sousa, A.J, Marsh, S., Brito, G. Abreu, M.M. (2011) Imaging spectroscopy answers to acid mine drainage detection at S. Domingos, Iberian Pyrite Belt, Portugal. Comunicações Geológicas, 98, 61-71. Rivard, B., Feng, J., Gallie, A., Sanchez-Azofeifa, A. 
(2008). Continuous wavelets for the improved use of spectral libraries and hyperspectral data. Remote Sensing of Environment, 112, 2850-2862

Roberts, D.A., Gardner, M., Church, R., Ustin, S., Scheer, G., Green, R.O. (1998). Mapping Chaparral in the Santa Monica Mountains Using Multiple Endmember Spectral Mixture Models. Remote Sensing of Environment, 65, 267-279.

Rogge, D.M., Rivard, B., Zhang, J., Sanchez, A., Harris, J., Feng, J. (2007). Integration of spatial-spectral information for the improved extraction of endmembers. Remote Sensing of Environment 110: 287-303.

Singer, P.C., Stumm, W. (1970). Acidic mine drainage: the rate-determining step. Science, 167: 1121-1123.

Smith, A.M., Hudson-Edwards, C.A., Dubbin, W.E., Wright, K. (2006). Dissolution of jarosite $\left[\mathrm{KFe}_{3}\left(\mathrm{SO}_{4}\right)_{2}(\mathrm{OH})_{6}\right]$ at pH 2 and 8: Insights from batch experiments and computational modelling. Geochimica et Cosmochimica Acta 70: 608-621.

Sousa, P., Sousa, A.J. (2000). Sistema ANDAD, CVRM-Centro de Geosistemas, IST, Lisbon.

Swayze, G.A., Clark, R.N., Pearson, R.M., Livo, K.E. (1996). Mapping Acid-Generating Minerals at the California Gulch Superfund Site in Leadville, Colorado Using Imaging Spectroscopy.Proc. of the 6th AVIRIS Airborne Geoscience Workshop. http://popo.jpl.nasa.gov/docs/workshops/96_docs/34.PDF

Swayze, G.A., Smith, K.S., Clark, R.N., Sutley, S.J., Pearson, R.M., Vance, J.S., Hageman, P.L., Briggs, P.H., Meier, A.L., Singleton, M.J., Roth, S. (2000). Using imaging spectroscopy to map acidic mine waste. Environmental Science and Technology, 34: 47-4.

Tavares, M.T., Sousa, A.J., Abreu, M.M. (2008). Ordinary kriging and indicator kriging in the cartography of trace elements contamination in São Domingos mining site (Alentejo, Portugal). Journal of Geochemical Exploration 98: 43-56.

Tavares, M.T, Abreu, M.M, Vairinho, M.M., Sousa, A.J., Quental, L. (2009). Comportamento geoquímico de alguns elementos vestigiais na envolvente das Minas de S. Domingos, Alentejo: áreas da Tapada e do Telheiro. Revista de Ciências Agrárias, 32 (1): $182-194$.

Zabcic, N., Ong, C., Mueller, A., Rivard, B. (2005). Mapping Surface pH Using Airborne Hyperspectral Imagery at the Sotiel-Migollas Mine, Spain. Proceedings of 4th EARSeL Workshop on Imaging Spectroscopy. New quality in environmental studies. Zagajewski B., Sobczak M., Wrzesień M., (eds) C EARSeL and Warsaw University, Warsaw.

\section{Figures}

\section{Legends}

Figure 1. Methodological approach.

Figure 2. a) General view of the area related to mining activities and main subareas for data collection overlayed on geocoded and mosaiced fligthlines of the HyMap ${ }^{\mathrm{TM}}$ sensor. b) Fligthline of detailed study area, black rectangle of 2a), with subset area and soil and spectra samples location (white squares, SD-S. Domingos).

Figure 3. Examples of low pH minerals spectra from laboratory measurements (a), the field spectra (b) and image retrieved endmembers (c). Reflectance values are given in $\%$ in two digit numbers of the nearest spectrum.

Figure 4. Spectral Angle Mapper algorithm of field spectra of Table II, and details of \% and coefficient of variation (CV) of each class. Redyellow-brown colors show increase of $\mathrm{pH}$ values based on minerals associations.

Figure 5. Spectral Angle Mapper algorithm of endmembers retrieved from the HyMap ${ }^{\mathrm{TM}}$ image. Legend key for minerals correlations in Table II, and details of $\%$ and coefficient of variation of each class. Red-yellow-brown colours show increase of pH values based on mineral associations.

Figure 6. Mineralogical correlation $(\geq 0.80)$ map of AMD with increasing $\mathrm{pH}$ from red through yellow to brown classes and average spectra below (normal-left, and right-continuum removal- right) of the classes mapped. Two digit numbers in graphs correspond to reflectance values of the nearest spectrum.

\section{Tables}

Table I. Minerals from the USGS spectral library (Clark et al., 1993) presenting high correlations and with Correlation Matrix Name (CMN) adopted.

Table II. Correlation coefficients of field spectra (subareas of Figure 2. a) and endmembers expressed in USGS spectral library minerals following CMN nomenclature of Table I.

Table III. Detail of input spectra, areas and coefficients of variation (CV) of the intermediate and final maps. 


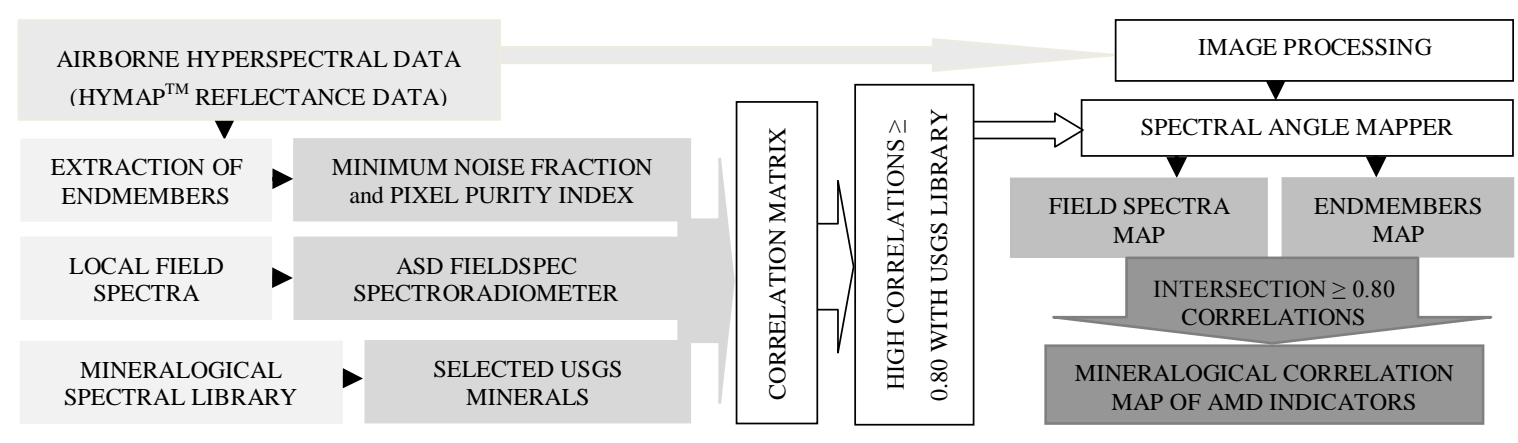

Figure 1. Methodological approach.

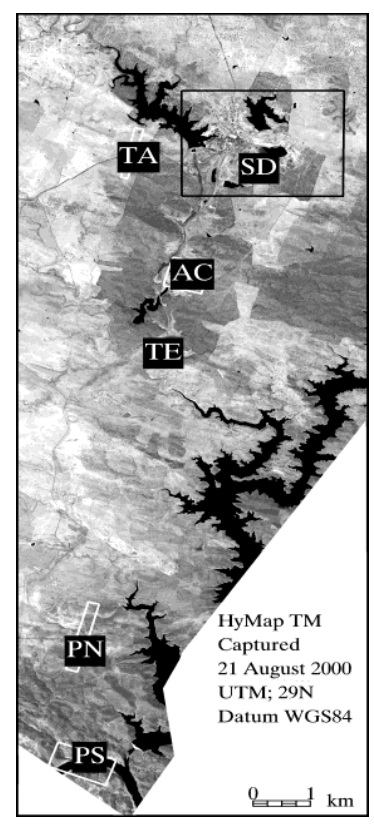

a)

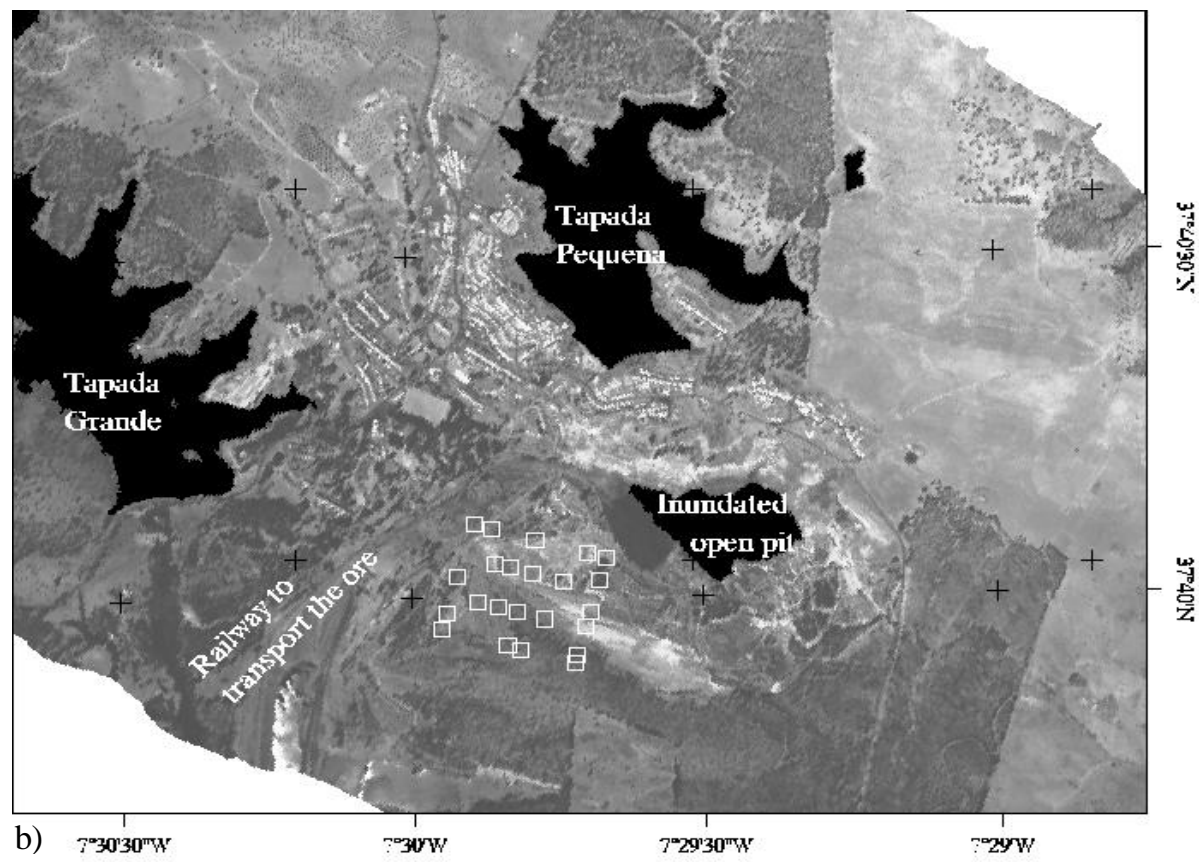

b) $7^{0} 30^{0} 30^{m} \mathrm{~W}$

Figure 2. a) General view of the area related to mining activities and main subareas for data collection overlayed on geocoded and mosaiced fligthlines of the HyMap ${ }^{\mathrm{TM}}$ sensor. b) Fligthline of detailed study area, black rectangle of 2a), with subset area and soil and spectra samples location (white squares, SD-S. Domingos). 


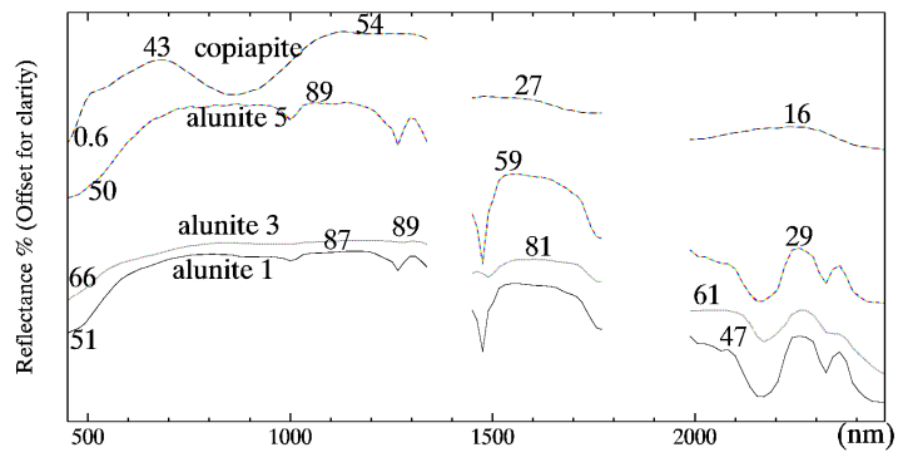

a) USGS spectral library (Clark et al., 1993).

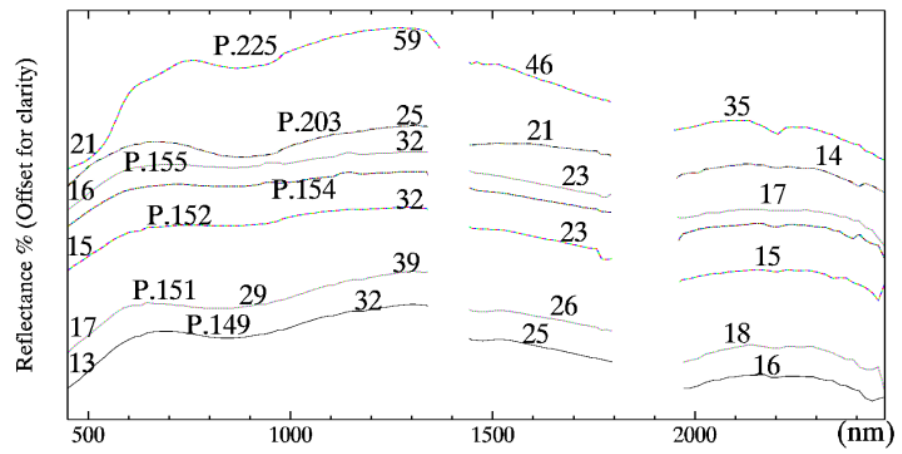

b) ASD FieldSpecPro.

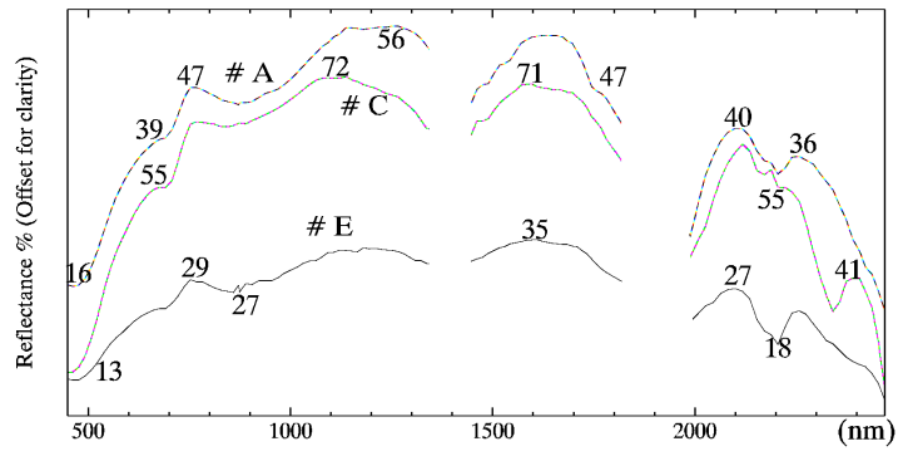

c) Image retrieved endmembers.

Figure 3. Examples of low pH minerals spectra from laboratory measurements (a), the high correlated field spectra (b) and image retrieved endmembers (c). Reflectance values are given in \% in two digit numbers corresponding to the nearest spectrum. 


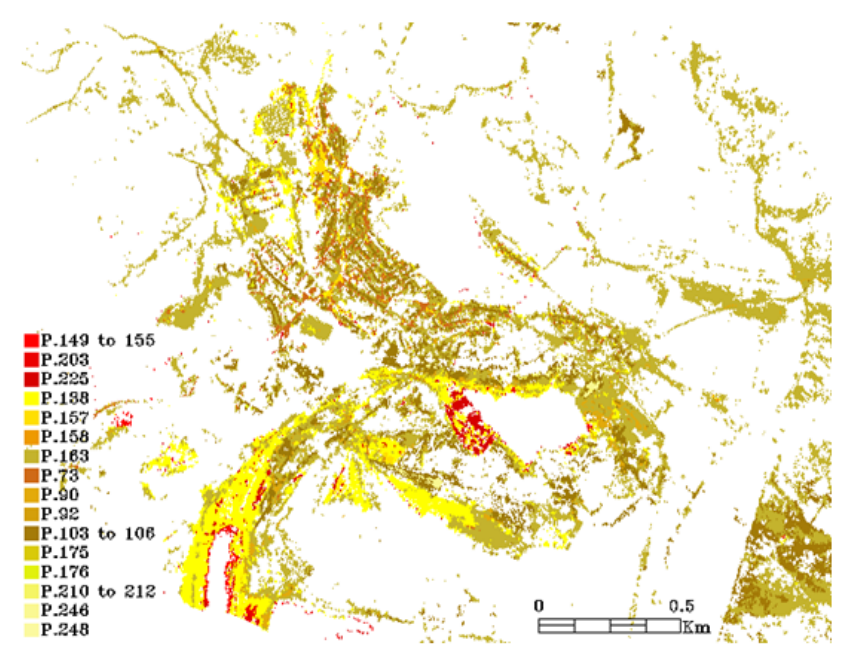

\begin{tabular}{lll|llc}
$\begin{array}{l}\text { Field } \\
\text { Spectra }\end{array}$ & $\%$ & CV & $\begin{array}{l}\text { Field } \\
\text { spectra }\end{array}$ & $\%$ & CV \\
\hline Unclassified & 79.348 & & & & \\
TE-73 & 0.809 & 0.244 & PS-155 & 0.005 & 0.339 \\
TE-90 & 0.381 & 0.189 & PS-157 & 0.282 & 0.241 \\
TE-92 & 0.129 & 0.222 & PS-158 & 0.014 & 0.199 \\
PN-103 & 0.040 & 0.162 & PS-163 & 11.319 & 0.194 \\
PN-103-6 & 1.700 & 0.173 & PN-175 & 0.018 & 0.167 \\
PS-137 & 1.926 & 0.233 & PN-176 & 0.011 & 0.185 \\
PS-138 & 3.286 & 0.286 & AC-203 & 0.049 & 0.224 \\
PS-149 & 0.016 & 0.151 & SD-212 & 0.056 & 0.116 \\
PS-151 & 0.002 & 0.238 & SD-225 & 0.441 & 0.487 \\
PS-152 & 0.019 & 0.548 & SD-246 & 0.070 & 0.129 \\
PS-154 & 0.057 & 0.596 & SD-248 & 0.020 & 0.135 \\
\hline
\end{tabular}

Figure 4. Spectral Angle Mapper algorithm of field spectra of Table II, and details of \% and coefficient of variation $(\mathrm{CV})$ of each class. Red-yellow-brown colors show increase of $\mathrm{pH}$ values based on minerals associations.

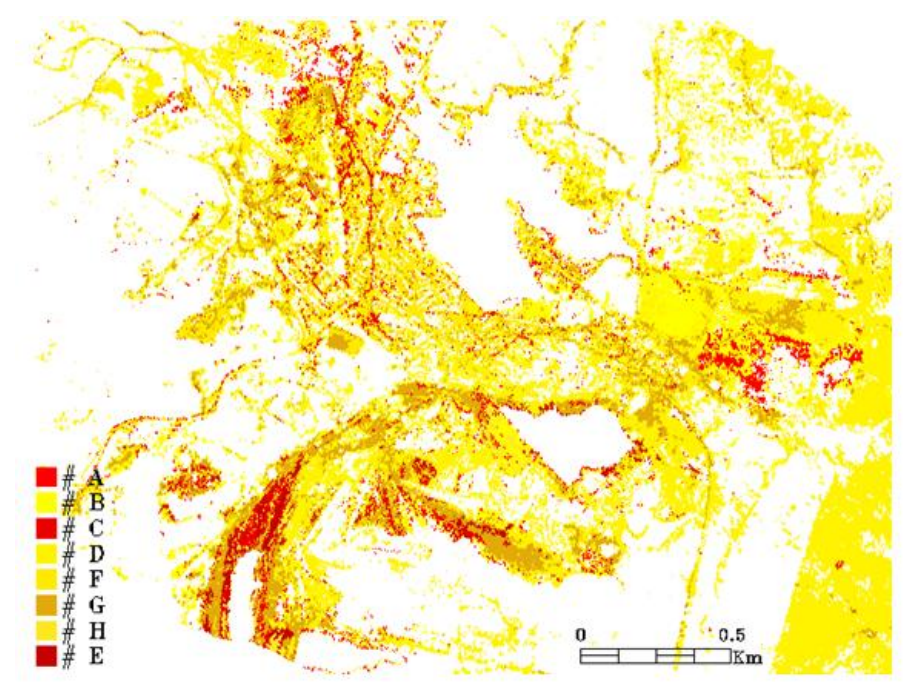

\begin{tabular}{lll}
$\begin{array}{l}\text { Endmember } \\
\text { spectra }\end{array}$ & $\%$ & $\mathrm{CV}$ \\
\hline Unclassified & 62.499 & - \\
\# A & 1.494 & 0.246 \\
\# B & 8.231 & 0.251 \\
\# C & 1.397 & 0.294 \\
\# D & 16.094 & 0.179 \\
\# E & 0.659 & 0.299 \\
\# F & 3.154 & 0.232 \\
\# G & 5.756 & 0.243 \\
\# H & 0.716 & 0.404
\end{tabular}

Figure 5. Spectral Angle Mapper algorithm of endmembers retrieved from the HyMapTM image. Legend key for minerals correlations in Table II, and details of $\%$ and coefficient of variation of each class. Red-yellow-brown colours show increase of $\mathrm{pH}$ values based on mineral associations. 

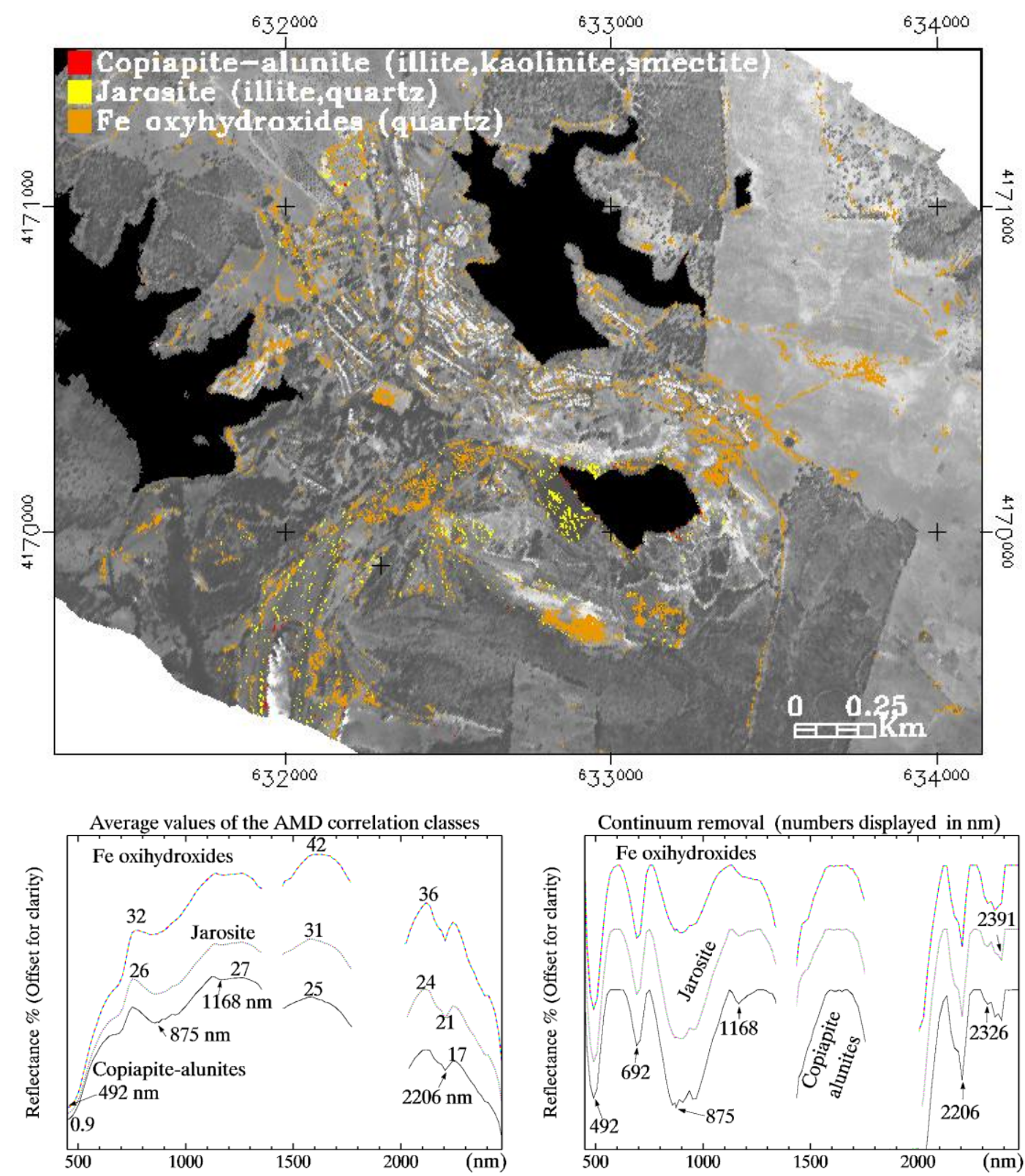

Figure 6. Mineralogical correlation $(\geq 0.80)$ map of AMD with increasing $\mathrm{pH}$ from red through yellow to brown classes and average spectra below (normal-left and continuum removal- right) of the classes mapped. Two digit numbers in graphs correspond to reflectance values of the nearest spectrum. 
Table I. Minerals from the USGS spectral library (Clark et al., 1993) presenting high correlations and with Correlation Matrix Name (CMN) adopted.

\begin{tabular}{|c|c|c|c|c|c|}
\hline \multicolumn{2}{|c|}{ USGS Spectral library filename } & \multirow{2}{*}{$\begin{array}{l}\mathrm{CMN} \\
\mathrm{aA}\end{array}$} & \multicolumn{2}{|c|}{ USGS Spectral library filename } & \multirow{2}{*}{$\begin{array}{l}\text { CMN } \\
\text { J3 }\end{array}$} \\
\hline a-alunit & Ammonioalunite NMNH145596 & & jarosit3 & Jarosite GDS100 Na-Sy 90C & \\
\hline a-jarosi & Ammonio-jarosite SCR-NHJ & $\mathrm{aJ}$ & jarosit4 & Jarosite GDS101 Na-Sy 200 & $\mathrm{~J} 4$ \\
\hline a-smecti & Ammonio-Smectite GDS86 & $\mathrm{aS}$ & jarosit5 & Jarosite GDS24 Na & J5 \\
\hline alunite1 & Alunite GDS84 Na03 & A1 & jarosit6 & Jarosite JR2501 K & J6 \\
\hline alunite2 & Alunite GDS83 Na63 & $\mathrm{A} 2$ & jarosit7 & Jarosite NMNH95074-1 Na & $\mathrm{J} 7$ \\
\hline alunite 3 & Alunite GDS82 Na82 & A3 & jarosit8 & Jarosite WS368 Pb & $\mathrm{J} 8$ \\
\hline alunite4 & Alunite AL706 Na & A4 & jarosit9 & Jarosite SJ-1 H3O - 10-20\% & J9 \\
\hline alunite5 & Alunite HS295.3B & A5 & kaolini1 & Kaolinite CM9 & $\mathrm{K}$ \\
\hline Copiapit & Copiapite GDS21 & Co & kaolini2 & Kaolinite KGa-1 (wxyl) & $\mathrm{K} 2$ \\
\hline chlorit4 & Chlorite SMR-13.c 45-60um & $\mathrm{C} 4$ & kaolini3 & Kaolinite KGa-2 (pxyl) & $\mathrm{K} 3$ \\
\hline chlorit5 & Chlorite SMR-13.d 30-45um & $\mathrm{C} 5$ & kaolini4 & Kaolinite KL502 (pxyl) & K4 \\
\hline chlorit6 & Chlorite SMR-13.e <30um & C6 & kaolini5 & Kaolinite GDS11 <63um & $\mathrm{K} 5$ \\
\hline Ferrihyd & Ferrihydrite GDS75 & $\mathrm{F}$ & kaolini6 & Kaolinite CM3 & K6 \\
\hline goethit1 & Goethite WS222 & G1 & kaolini7 & Kaolinite CM5 & $\mathrm{K} 7$ \\
\hline goethit2 & Goethite HS36.3 & G2 & kaolini8 & Kaolinite CM7 & K8 \\
\hline goethit3 & Goethite WS219 & G3 & illite1 & Illite GDS4 & I1 \\
\hline goethit4 & Goethite WS220 & G4 & illite2 & Illite IMt-1.a & $\mathrm{I} 2$ \\
\hline Hematit1 & Hematite $2 \%+98 \%$ Qtz GDS76 & $\mathrm{H} 1$ & illite3 & Illite IMt-1.b <2um & I3 \\
\hline Hematit2 & Hematite GDS27 & $\mathrm{H} 2$ & illite4 & Illite IL101 (2M2) & I4 \\
\hline Hematit3 & Hematite GDS69.a 150-250u & H3 & illite5 & Illite IL105 (1Md) & I5 \\
\hline Hematit4 & Hematite GDS69.b 104-150u & $\mathrm{H} 4$ & Lepidocr & Lepidocrosite GDS80 (Sy) & $\mathrm{L}$ \\
\hline Hematit5 & Hematite GDS69.c 60-104um & H5 & pyrite1 & Pyrite HS35.3 & Py1 \\
\hline Hematit6 & Hematite GDS69.d 30-45um & H6 & pyrite 2 & Pyrite S142-1 & Py 2 \\
\hline Hematit7 & Hematite GDS69.e 20-30um & $\mathrm{H} 7$ & pyrite 3 & Pyrite S26-8 & Py3 \\
\hline Hematit8 & Hematite GDS69.f 10-20um & $\mathrm{H} 8$ & pyrite 4 & Pyrite S29-4 & Py4 \\
\hline Hematit9 & Hematite GDS69.g <10um & H9 & pyrite 5 & Pyrite S30 & Py5 \\
\hline Hematite & Hematite HS45.3 & $\mathrm{Ha}$ & quartz2 & GDS31 0-74um fr & Q2 \\
\hline Hematitb & Hematite WS161 & $\mathrm{Hb}$ & quartz3 & Quartz HS32.4B & Q3 \\
\hline Hematitc & Hematite FE2602 & $\mathrm{Hc}$ & quartz4 & Quartz GDS74 Sand Ottawa & Q4 \\
\hline Jarosit1 & Jarosite GDS99 K-y 200C & $\mathrm{J} 1$ & Sulfur & Sulfur GDS94 & $\mathrm{S}$ \\
\hline Jarosit2 & Jarosite GDS98 K-Sy 90C & $\mathrm{J} 2$ & & & \\
\hline
\end{tabular}


Table II. Correlation coefficients of field spectra (subareas of Figure 2. a) and endmembers expressed in USGS spectral library minerals following CMN nomenclature of Table I.

\begin{tabular}{|c|c|c|}
\hline FIELD SPECTRA & $\geq 0.90$ & $0.80 \leq \mathrm{N}<0.90$ \\
\hline TE-73 & $\mathrm{J}(3,8)$ & $\mathrm{J}(2,4,5,6,7,9), \mathrm{Q}(3,4), \mathrm{G}(3,4), \mathrm{H} 1, \mathrm{~L}$ \\
\hline TE-90 & $\mathrm{L}, \mathrm{G} 3, \mathrm{~J}(2,3,6,7,8,9)$ & $\mathrm{G}(1,4), \mathrm{I}(1,5) . \mathrm{J}(1,4,5), \mathrm{F}, \mathrm{H} 1$ \\
\hline TE-92 & $\mathrm{J}(2,3,6,8,9) \mathrm{L}$ & $\mathrm{G}(1,3,4), \mathrm{J}(1,4,5,7), \mathrm{I} 1, \mathrm{~F}, \mathrm{H} 1$ \\
\hline PN-103 & $\mathrm{G}(1,3,4), \mathrm{I} 5, \mathrm{~J} 8, \mathrm{H}(1,2), \mathrm{Q} 4, \mathrm{~L}, \mathrm{~F}$ & $\mathrm{~J}(3,4,5,6,7), \mathrm{H}(\mathrm{a}, \mathrm{b}, \mathrm{c}, 8,9), \mathrm{Q}(2,3), \mathrm{I} 1, \mathrm{C}(5,6), \mathrm{Py} 2$ \\
\hline PN-103-6 & $\mathrm{G}(1,3,4), \mathrm{H}(1,2) \mathrm{J} 8$ & $\mathrm{~F}, \mathrm{~J}(3,5,6,7), \mathrm{I} 1, \mathrm{Q}(2,3), \mathrm{H}(\mathrm{a}, \mathrm{b}, \mathrm{c}, 9), \mathrm{C} 6$ \\
\hline PS-137 & $\mathrm{L}, \mathrm{G}(1,3,4, \mathrm{H}(1,2), \mathrm{Q} 4, \mathrm{~J}(6,7,8), \mathrm{I} 5$ & $\mathrm{F}, \mathrm{J}(2,3,4,5,9), \mathrm{Q}(2,3), \mathrm{I} 1, \mathrm{H}(\mathrm{a}, \mathrm{b}, \mathrm{c}, 9), \mathrm{C} 6, \mathrm{Py} 2$ \\
\hline PS-138 & $\mathrm{J}(2,3,9)$ & $\mathrm{aJ}, \mathrm{J}(1,6)$ \\
\hline PS-149 & $\mathrm{Co}, \mathrm{A} 3$ & $\mathrm{~A}(1,2,4,5,6) \mathrm{aA}, \mathrm{aI}, \mathrm{aS}, \mathrm{I} 4, \mathrm{~K}(3,4)$ \\
\hline PS-151 & $\mathrm{Co}, \mathrm{A} 3$ & $\mathrm{~A}(\mathrm{a}, 1,2,4,5,6), \mathrm{aI}$ aS, I4, K $(3,4,6)$ \\
\hline PS-152 & $\mathrm{A}(1,3,5),, \mathrm{Co}, \mathrm{aI}$ & $\mathrm{I} 4, \mathrm{~A}(\mathrm{a}, 2,4,6), \mathrm{S}, \mathrm{K}(1,2,3,4,5,6,7)$ \\
\hline PS-154 & $\mathrm{A}(1,3,5), \mathrm{Co}, \mathrm{aI}$ & $\mathrm{I} 4, \mathrm{~A}(\mathrm{a}, 2,4,6), \mathrm{S}, \mathrm{K}(1,2,3,4,5,6,7)$ \\
\hline PS-155 & $\mathrm{A}(1,3,5), \mathrm{Co}, \mathrm{Ai}$ & $\mathrm{A}(\mathrm{a}, 2,4,6), \mathrm{I} 4, \mathrm{aS}, \mathrm{K}(1,2,3,4,5,6,7)$ \\
\hline PS-157 & $\mathrm{J}(2,3,9)$ & $\mathrm{J}(\mathrm{a}, 1,4,6,5,7,8), \mathrm{L}, \mathrm{G} 3$ \\
\hline PS-158 & $\mathrm{J}(2,3,4,6,8)$ & $\mathrm{J}(1,5,7,9), \mathrm{L}, \mathrm{H} 1, \mathrm{G}(1,3,4), \mathrm{I} 1, \mathrm{Q} 4$ \\
\hline PS-163 & $\mathrm{L}$ & $\mathrm{J}(2,3,4,5,6,7,8,9) \mathrm{G}(1,3,4), \mathrm{H}(1,2), \mathrm{I} 1, \mathrm{~F}, \mathrm{Q} 4$ \\
\hline PN-175 & $\mathrm{F}, \mathrm{G}(1,3,4), \mathrm{I}(1,5), \mathrm{J}(6,7,8), \mathrm{L}$ & $\mathrm{C}(4,5,6), \mathrm{H}(1,2), \mathrm{J}(2,3,4,5), \mathrm{Py} 2, \mathrm{Q}(2,3,4)$ \\
\hline PN-176 & $\mathrm{F}, \mathrm{G}(1,3,4), \mathrm{H}(1,2), \mathrm{I} 5, \mathrm{~J} 8, \mathrm{~L}, \mathrm{Q}(3,4)$ & $\mathrm{C} 6, \mathrm{H}(\mathrm{a}, \mathrm{b}, \mathrm{c}, 8,9), \mathrm{I} 1, \mathrm{~J}(6,7), \mathrm{Py} 2, \mathrm{Q} 2$ \\
\hline AC-203 & & $\mathrm{A}(\mathrm{a}, 1,3), \mathrm{aS}, \mathrm{Co}, \mathrm{I}, \mathrm{K}(2,3,6,7)$ \\
\hline SD-210 & $\mathrm{F}, \mathrm{G}(1,3,4), \mathrm{H}(\mathrm{b}, \mathrm{c}, 1,2,9), \mathrm{I} 5, \mathrm{~J} 8, \mathrm{~L}, \mathrm{Py} 2, \mathrm{Q} 4$ & $\mathrm{C} 6, \mathrm{H}(\mathrm{a}, 3,4,6,7,8), \mathrm{J}(3,4,5,6,7), \mathrm{Q}(2,3), \mathrm{Py} 5$ \\
\hline SD-212 & $\mathrm{F}, \mathrm{G}(1,3,4), \mathrm{H}(1,2), \mathrm{I} 5, \mathrm{~J} 8, \mathrm{~L}, \mathrm{Q} 4$ & $\mathrm{C} 6, \mathrm{H}(\mathrm{a}, \mathrm{b}, \mathrm{c}, 8,9), \mathrm{I} 1, \mathrm{~J}(2,3,4,5,6,7,9), \mathrm{Py} 2, \mathrm{Q}(2,3)$ \\
\hline SD-225 & & $\mathrm{Co}, \mathrm{A}(\mathrm{a}, 1,3)$ \\
\hline SD-246 & $\mathrm{F}, \mathrm{G}(1,3,4), \mathrm{H}(1,2), \mathrm{I} 5, \mathrm{~J}(6,7,8), \mathrm{L}$ & $\mathrm{C} 6, \mathrm{H}(\mathrm{b}, \mathrm{c}, 3,8,9), \mathrm{I} 1, \mathrm{~J}(2,3,4,5,9), \mathrm{Py} 2, \mathrm{Q}(2,3,4)$ \\
\hline SD-248 & $\mathrm{F}, \mathrm{G}(1,3,4), \mathrm{G}(3,4), \mathrm{H}(\mathrm{c}, 1,2), \mathrm{I} 5, \mathrm{~J}(7,8), \mathrm{L}, \mathrm{Q} 4$ & $\mathrm{C} 6, \mathrm{H}(\mathrm{b}, 3,7,8,9), \mathrm{I} 1, \mathrm{~J}(2,3,4,5,6,9), \mathrm{Py} 2, \mathrm{Q}(2,3)$ \\
\hline ENDMEMBERS & $>=0.90$ & $0.80=<\mathrm{N}<0.90$ \\
\hline \# A & & $\mathrm{aS}, \mathrm{Co}, \mathrm{aA}, \mathrm{A} 3$ \\
\hline \# B & & $\mathrm{J}(2,3,9), \mathrm{I} 1$ \\
\hline \# C & $\mathrm{A}(1,3), \mathrm{Co}$ & $\mathrm{A}(\mathrm{a}, 2,4,5,6), \mathrm{aI}, \mathrm{as}, \mathrm{I} 4, \mathrm{~K}(3,4,6,7)$ \\
\hline \# D & & $\mathrm{J}(2,9)$ \\
\hline \# E & $\mathrm{A}(1,3,5,6), \mathrm{Co}, \mathrm{aI}$ & $\mathrm{A}(\mathrm{a}, 2,4), \mathrm{aS}, \mathrm{I} 4, \mathrm{~K}(1,2,3,4,5,6,7)$ \\
\hline \# F & & $\mathrm{aJ}, \mathrm{J}(2,3,9), \mathrm{Q} 1$ \\
\hline \# G & & $\mathrm{F}, \mathrm{G}(3,4), \mathrm{H} 1, \mathrm{I} 1, \mathrm{~J}(2,3,6,7,8,9), \mathrm{L}, \mathrm{Q} 4$ \\
\hline \# H & & $\mathrm{J}(2,3,9), \mathrm{Aj}$ \\
\hline
\end{tabular}

